This item was submitted to Loughborough's Research Repository by the author.

Items in Figshare are protected by copyright, with all rights reserved, unless otherwise indicated.

\title{
High-speed laser image analysis of plume angles for pressurised metered dose inhalers: the effect of nozzle geometry
}

\section{PLEASE CITE THE PUBLISHED VERSION}

http://dx.doi.org/10.1208/s12249-016-0564-5

\section{PUBLISHER}

Springer (c) American Association of Pharmaceutical Scientists

\section{VERSION}

AM (Accepted Manuscript)

\section{PUBLISHER STATEMENT}

This work is made available according to the conditions of the Creative Commons Attribution-NonCommercialNoDerivatives 4.0 International (CC BY-NC-ND 4.0) licence. Full details of this licence are available at: https://creativecommons.org/licenses/by-nc-nd/4.0/

\section{LICENCE}

CC BY-NC-ND 4.0

\section{REPOSITORY RECORD}

Chen, Yang, Paul M. Young, Seamus Murphy, David F. Fletcher, Edward Long, David Lewis, Tanya Church, and Daniela Traini. 2016. "High-speed Laser Image Analysis of Plume Angles for Pressurised Metered Dose Inhalers: The Effect of Nozzle Geometry". Loughborough University. https://hdl.handle.net/2134/23589. 


\section{$\mathrm{AQ}_{2}$}

High-Speed Laser Image Analysis of Plume Angles for Pressurised Metered Dose Inhalers: The Effect of Nozzle Geometry

\section{AQ1}

Yang Chen 1 ,

Phone +61-2-91140370

Emailyche9443@uni.sydney.edu.au

Paul M. Young 1

Seamus Murphy 2

David F. Fletcher 3

Edward Long 4

David Lewis 5

Tanya Church 5

Daniela Traini 1

1 Respiratory Technology, Woolcock Institute of Medical Research and Discipline of Pharmacology, Sydney Medical School, The University of Sydney, Sydney, NSW, 2037 Australia

2 Oxford Lasers Ltd, Unit 8, Moorbrook Park, Didcot, Oxfordshire, UK

3 School of Chemical and Biomolecular Engineering, The University of Sydney, Sydney, NSW, 2006 Australia

4 Wolfson School of Mechanical and Manufacturing Engineering, Loughborough

University, Loughborough, Leicestershire, LE11 3TU UK 
5 Chiesi Ltd, Units T1 - T3, Bath Rd. Ind.

Est., Chippenham, Wiltshire, SN14 0AB UK

\section{Abstract}

The aim of this study is to investigate aerosol plume geometries of pressurised metered dose inhalers (pMDIs) using a high-speed laser image system with different actuator nozzle materials and designs. Actuators made from aluminium, PET and PTFE were manufactured with four different nozzle designs: cone, flat, curved cone and curved flat. Plume angles and spans generated using the designed actuator nozzles with four solution-based pMDI formulations were imaged using Oxford Lasers EnVision system and analysed using EnVision Patternate software. Reduced plume angles for all actuator materials and nozzle designs were observed with pMDI formulations containing drug with high co-solvent concentration (ethanol) due to the reduced vapour pressure. Significantly higher plume angles were observed with the PTFE flat nozzle across all formulations, which could be a result of the nozzle geometry and material's hydrophobicity. The plume geometry of pMDI aerosols can be influenced by the vapour pressure of the formulation, nozzle geometries and actuator material physiochemical properties.

\section{KEY WORDS}

aerosol

electrostatics

electrostatics nozzle designs

plume geometry

\section{INTRODUCTION}

Pressurised metered dose inhalers (pMDI) are portable and convenient devices that have been widely used in inhalation therapy to deliver multiple doses of aerosolised medication to the pulmonary system, especially for the treatment of asthma. Since its first development in 1950s by $3 \mathrm{M}$ Riker Laboratories (1), the basic design of the pMDI remains almost unchanged, except for the transition of propellants from 
chlorofluorocarbons to more environmentally friendly hydrofluoroalkanes (HFAs) in the 1990s (2). The physical components of the pMDI include the following: a disposable canister where drug, liquid propellant and/or excipients are stored; a metering valve which ensures a correct dose of the formulation is delivered; and a plastic actuator for atomisation (3).

Besides coordination with patients' inhalation, the dose effectiveness of pMDI relies on the successful aerosolisation of the drug. The respiratory fraction of an active component delivered by pMDIs is often influenced by the aerosol plume properties, including plume velocity and spray geometry, which have direct correlations with oropharyngeal deposition and delivered dose (4). During actuation, the pressure force provided by the propellant causes the suspended and/or solubilised drug to form a liquid-gaseous spray that subsequently generates particles once both the propellant and co-solvent are evaporated. The plume of the spray and the size of the particles produced by the pMDI largely depend on the vapour pressure of the propellant, the ingredients of the formulation, the metering valve, the ambient environment and the actuator nozzle designs $(5,6)$.

Spray geometry analysis can be used to evaluate the pMDIs actuator nozzle's performance, and there are several methods that can be applied to assess this parameter. Originally, the aerosol plume was often evaluated through impingement of the spray on a piece of dye-talc-treated paper (7). In 1983, Benjamin et al. integrated thin layer chromatography into spray analysis with photographs of the plume (8). Since then, optical methods, including flash photography and high-speed video, have been frequently used to assess the spray dynamic of pMDIs (9-12). The advantages of photographic imaging methods are fast screening and ease of obtaining and analysing the data. However, the accuracy of the images provided by these techniques relies on the photography parameters include lens, shutter speed and illumination intensity.

Laser diagnostic methods such as laser diffraction, Laser Doppler Anemometer (LDA) and Phase Doppler Anemometer (PDA) have also been developed to provide better resolution of the plume spray and are often used in conjunction with photographic methods to deliver critical information on droplet size, velocity and mass volume of the plume $(13,14)$. However, these methods rely on the diffraction and refraction of light, and consequently, accurate measurements are limited by the droplet 
properties, such as colour, shape and density (15). The spray emitted from a pMDI is fast moving and transient; the plume contains multiphase aerosols with continuous propellant evaporation and generation of flow turbulence. These inherent characteristics of the pMDI aerosol introduce challenges when trying to obtain accurate results over the whole sample spray (16), with both optical and laser diagnostic tests.

A new platform that allows effective investigation of plume characteristics, especially for high-pressure aerosolised drugs, has been developed recently. The Oxford Laser EnVision system (Oxford Laser Ltd, Oxfordshire, UK) is designed to capture the transient nature of the aerosol plume using a safety enclosure, equipped with a high frequency camera, shot-pulsed laser light source and automatic image analysis software. This technique can be used to obtain a multitude of data relating to the generated aerosol including information about the aerosol, such as plume intensity, thermal properties and droplet size analysis. The advanced laser illumination of this technique enables the capture of images free from motion blur; hence, it is suitable for evaluation of atomisation process for pMDI aerosols $(17,18)$.

In recent years, there has been an increasing interest in aerosol electrostatics since they may play a role in aerosol plume properties and regional lung deposition. Aerosols emitted from a pMDI are charged through contact with device materials and other particles (19). This process is called triboelectrification and depends largely on the materials' properties. Studies using actuators made from different triboelectric materials have demonstrated aerosol charging to follow the triboelectric properties of the actuator materials, with formulation containing no drug and low co-solvent ( $1 \%$ ethanol) emitted from a cone-shaped nozzle design (20). The influence of nozzle design on aerosol electrostatic changing dynamics and performance for solution pMDI have also been analysed, using different orifice geometries, and results have shown increased throat deposition with reversed aerosol charge polarity for orifices with curved edges (21). While advances have been made with respect to understanding the relationship between charge generation and actuator orifice material and geometry, it is still not well understood whether the changes in deposition pattern are due to plume angle variations caused by the different nozzle designs and/or electrostatic forces between the charged particles. 
The pMDI nozzle geometry is important for the atomisation process; hence, differences in the orifice shape could influence the aerosols characteristics. The purpose of this study was to investigate the plume geometries of a series of solution pMDI aerosols containing HFA 134a, ethanol and beclomethasone dipropionate (BDP), emitted from different nozzle designs namely cone, flat, curved cone and curved flat (Fig. 1), using the Oxford Laser Envision system and to relate the findings to overall aerosol performance and previously investigated aerosol electrostatic charge profiles.

\section{Fig. 1}

Schematic representation of the four pMDI nozzle designs: cone, flat, curved cone and curved flat orifice, all with $0.3-\mathrm{mm}$ nominal orifice diameter and 1$\mathrm{mm}$ jet length

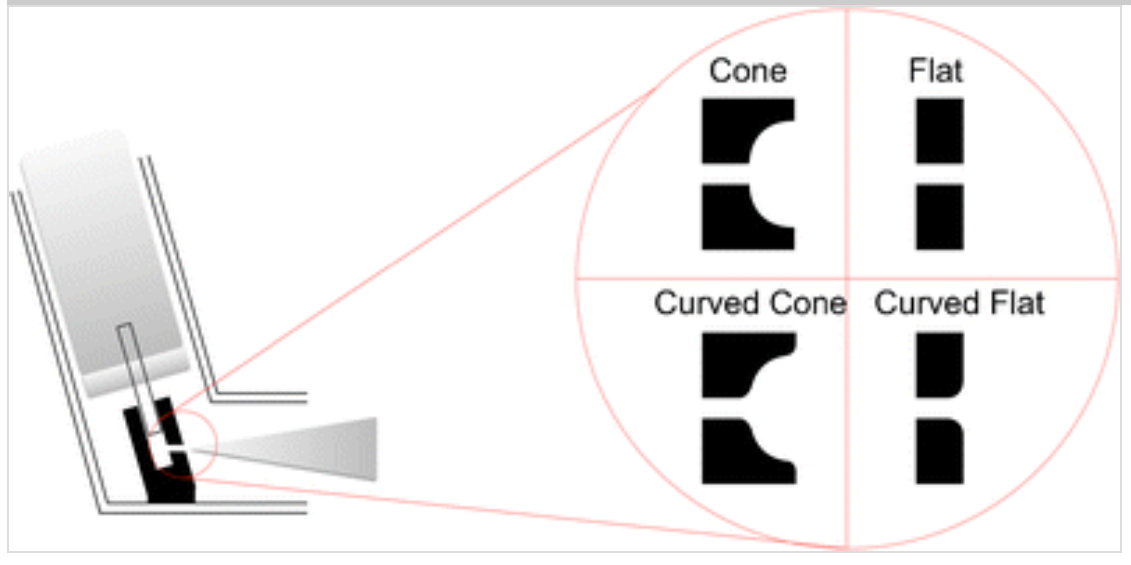

\section{MATERIALS AND METHODS}

\section{Actuator Materials and Manufacture}

Three materials, including aluminium (Aalco Metals Ltd, Cobham, UK), polyethylene terephthalate (PET) and polytetrafluoroethylene (PTFE) (Ensinger GmbH, Nufringen, Germany) were selected to manufacture the pMDI actuator nozzles. These materials represent different triboelectric charging properties, and their rank from positive to negative charge potential follows the order of aluminium $>$ PET $>$ PTFE (22). The nozzles had a $0.3-\mathrm{mm}$ nominal atomisation orifice diameter and $1-\mathrm{mm}$ jet length. Four different atomisation orifice geometries were manufactured namely cone, flat, curved cone and curved flat, designed using Siemens NX software and engineered with high-speed steel cutting tools (Fig. 1). A dimensional accuracy to within $\pm 0.01 \mathrm{~mm}$ was achieved and was 
confirmed for all designed nozzles using spatially calibrated microscope and MediaCybernetics Image-Pro software.

\section{Pressurised Metered Dose Inhaler Formulations}

Four pMDI formulations were prepared according to Table I and are referred as formulation $\mathrm{A}, \mathrm{B}, \mathrm{C}$ and $\mathrm{D}$ hereafter. The required co-solvent ethanol (Sigma-Aldrich Pty Ltd, Castle Hill, Australia) and beclomethasone dipropionate active pharmaceutical ingredient (BDP, Chiesi Farmaceutici S.p.A, Parma, Italy) were accurately weighted into C128P aluminium canisters (ID214, Batch 1002043-3, 18-ml brim capacity, Presspart Manufacturing Ltd, Lancashire, UK). The filled canisters were immediately crimped with a 50- $\mu$ l metering valve (ID201, batch BK0313029, Bespak Europe Ltd, Norfolk, UK) and pressured filled with 1,1,1,2-tetrafluoroethane (HFA 134a, Solvay Chemicals, Brussels, Belgium) propellant using a Pamasol Laboratory plant P2016 (Pamasol Willi Maäden AG, Pfaffikon, SZ). The solubility of the drug component was confirmed visually using glass canisters (Saint Gobain, France). All canisters were stored at ambient temperature for $24 \mathrm{~h}$ prior to testing.

\section{Table I}

Composition of the Pressurised Metered Dose Inhaler Formulations

\begin{tabular}{|l|l|l|l|l|}
\cline { 5 - 6 } \multicolumn{1}{|c|}{ pMDIs } & \multicolumn{1}{|c|}{$\begin{array}{c}\text { HFA 134a } \\
(\boldsymbol{w} / \boldsymbol{w} \%)\end{array}$} & \multicolumn{1}{|c|}{$\begin{array}{c}\text { Ethanol } \\
(\boldsymbol{w} / \boldsymbol{w} \%)\end{array}$} & $\begin{array}{c}\text { BDP } \\
(\boldsymbol{w} / \boldsymbol{w} \%)\end{array}$ & $\begin{array}{c}\text { Targeted dose } \\
(\boldsymbol{\mu g})\end{array}$ \\
\hline $\begin{array}{l}\text { Formulation } \\
\text { A }\end{array}$ & 100 & 0 & 0 & NA \\
\hline $\begin{array}{l}\text { Formulation } \\
\text { B }\end{array}$ & 99 & 1 & 0 & NA \\
\hline $\begin{array}{l}\text { Formulation } \\
\text { C }\end{array}$ & 85 & 15 & 0 & NA \\
\hline $\begin{array}{l}\text { Formulation } \\
\text { D }\end{array}$ & 85 & 14.9 & 0.1 & 50 \\
\hline
\end{tabular}

\section{Plume High-Speed Laser Imaging}

The pMDI plume angle of each formulation with each of the nozzle designs was evaluated using an Oxford Lasers EnVision laser-based imaging system equipped with a CMOS sensor Photron ${ }^{\circledR}$ FASTCAM MC1 camera and Oxford Lasers FireFLY pulsed diode laser illumination 
(illustrated in Fig. 2). The Fire FLY laser delivers a planer light sheet, orientated parallel to the plume emitted from the pMDI device. The camera is set up perpendicular to the light sheet to visualise the flow of the plume. The designed nozzles were mounted on an automated actuator system with a fixed platform (point of origin). One actuation event from the pMDI was sprayed into still air, and a high-speed image sequence was captured at $250 \mathrm{~Hz}$ over the full event. The EnVision Patternate software automatically analyses the intensity of each image of the spray and detects the fully formed plume with highest intensity from the captured sequence of images and analyses the plume geometry. All tests were performed in triplicate under general laboratory conditions (temperature $25^{\circ} \mathrm{C}$ and $\sim 60 \% \mathrm{RH}$ ).

\section{Fig. 2}

Schematic of the Oxford-laser high-speed laser image test setup

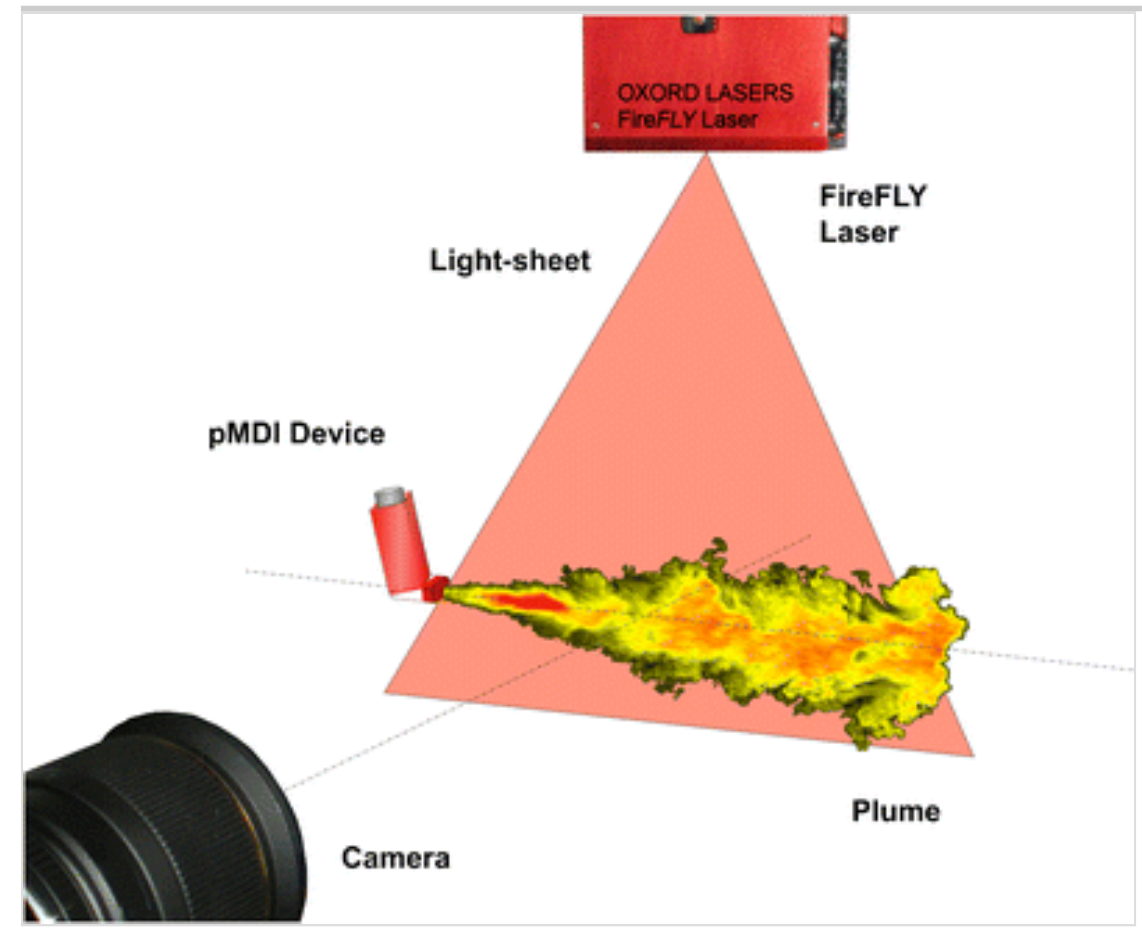

\section{Data Analysis}

All experiments were randomised. The plume angles and orientations for different nozzle designs and pMDI formulations were calculated by the EnVision Patternate software based on the laser image obtained for the fully formed spray. Plume span was measured for the fully formed plume at the distance of 2, 4, 6 and $8 \mathrm{~cm}$ to the orifice for all tests. Statistical analysis using one-way ANOVA (unstacked) was performed with STATPlus statistics software package (AnalySOft Inc., VA, USA), and significant difference was based on $p<0.05$. 


\section{RESULTS AND DISCUSSION}

Spray pattern analysis is a very important parameter for the quality and performance of metered dose inhalers. Many factors include actuator orifice diameter, vapour pressure, excipients and surfactant, as well as actuator materials $(9,23)$. In this study, the effect of different nozzle geometry and actuator material on pMDI aerosol plume angles was investigated using four formulations. The results are shown in Figs. 3, 4, 5 and 6 and are discussed below.

\section{Fig. 3}

Plume angles for three actuator materials and four types of the nozzle designs for formulation $\mathrm{A}(n=3 \pm \mathrm{SD})$

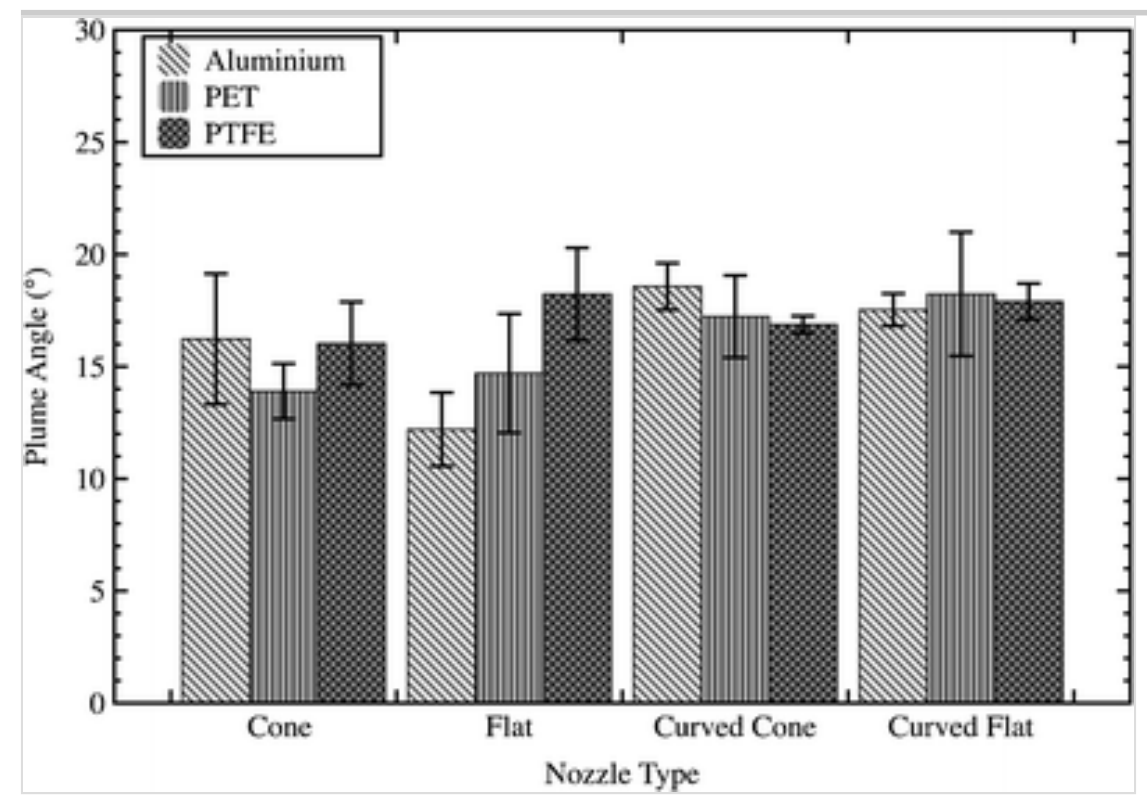

\section{Fig. 4}

Plume angles for three actuator materials and four types of the nozzle designs for formulation $\mathrm{B}(n=3 \pm \mathrm{SD})$ 


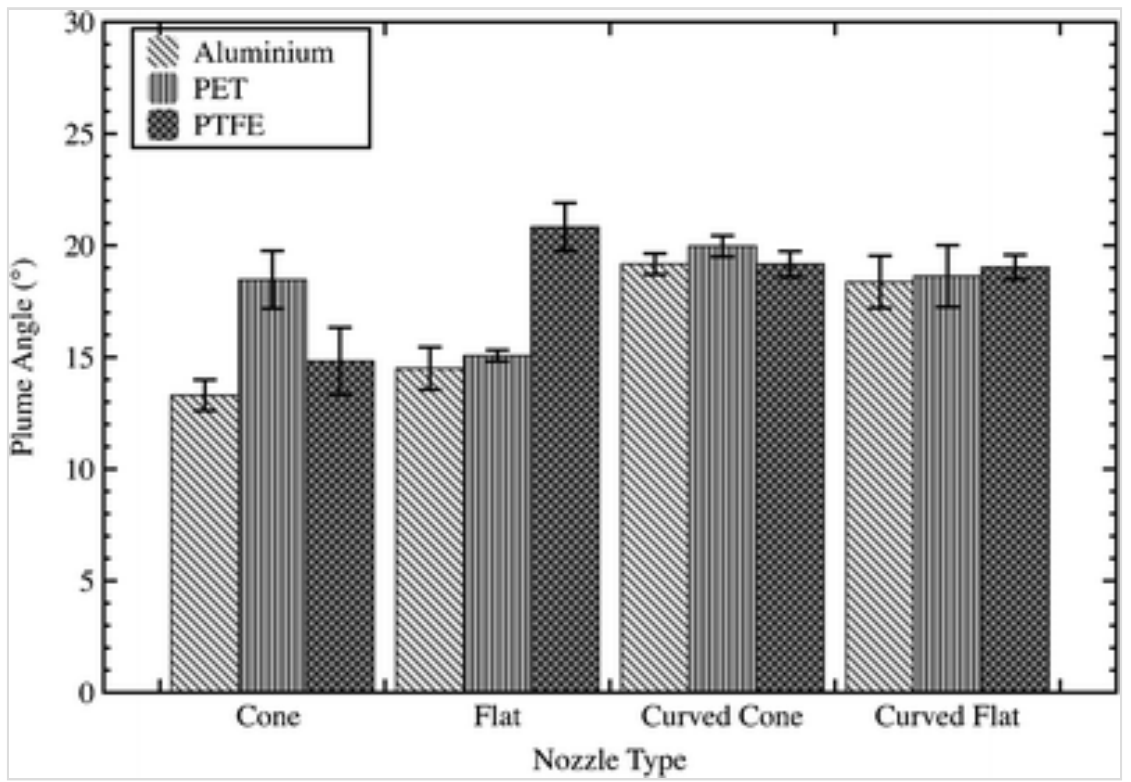

\section{Fig. 5}

Plume angles for three actuator materials and four types of the nozzle designs for formulation $\mathrm{C}(n=3 \pm \mathrm{SD})$

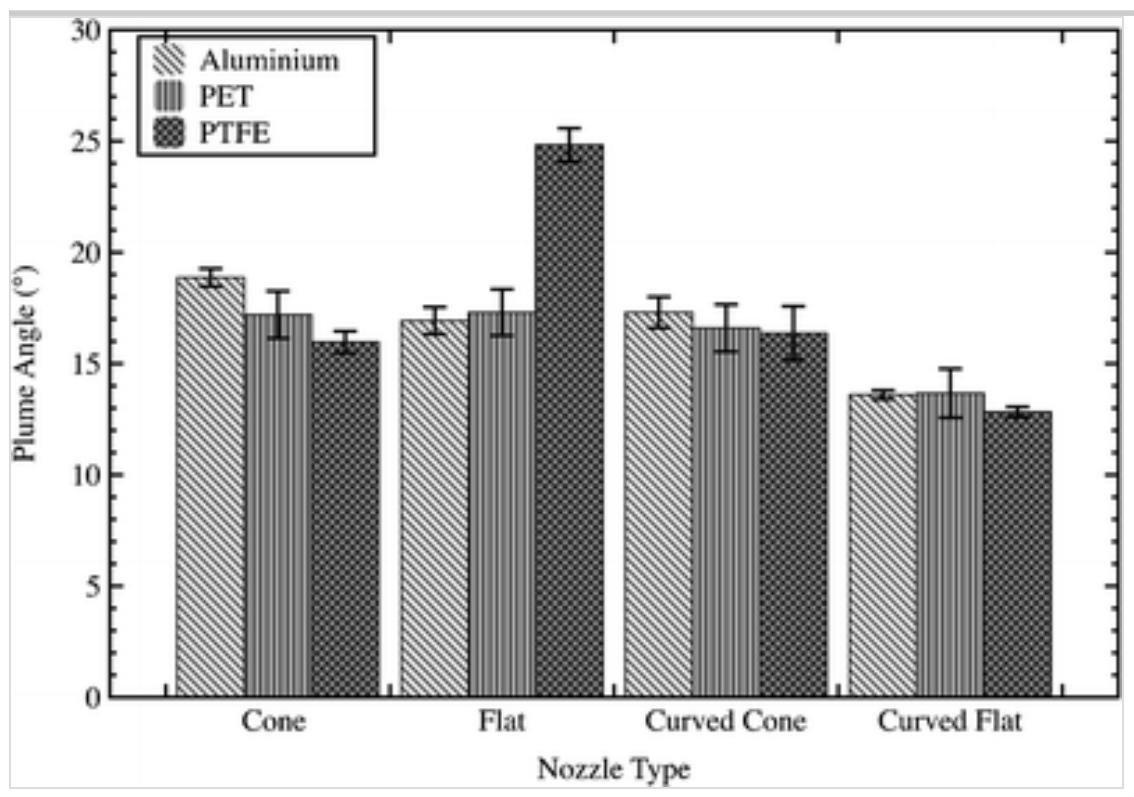

\section{Fig. 6}

Plume angles for three actuator materials and four types of the nozzle designs for formulation $\mathrm{D}(n=3 \pm \mathrm{SD})$ 


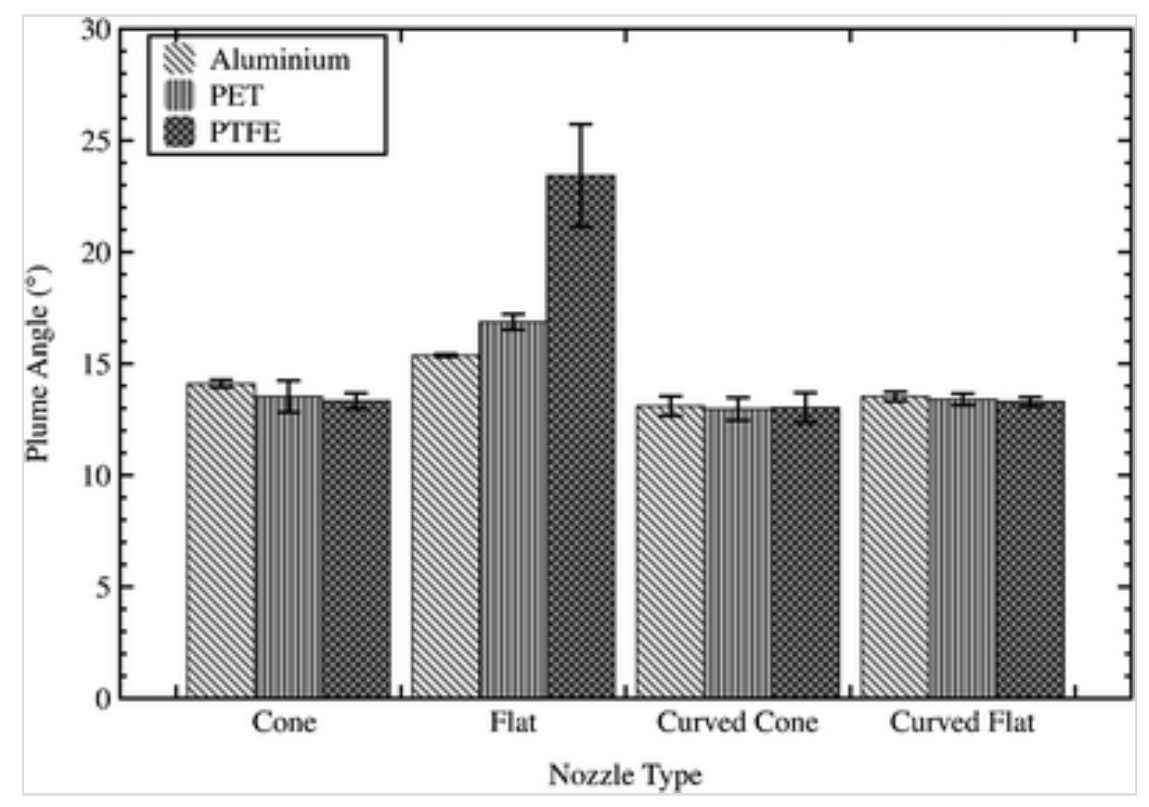

\section{Effect of Actuator Materials and Formulations on Plume Geometries}

The plume angles generated with propellant only formulation A, for all different nozzle designs and actuator materials, ranged between $12 \pm 1.64^{\circ}$ and $18.57 \pm 0.72^{\circ}$ (Fig. 3). Statistical analysis using one-way ANOVA comparison between the three different actuator materials for the same nozzle demonstrated no significant differences, except for the flat nozzle design.

In our previous study, all three actuator materials produced negative charged pMDI aerosols, where aluminium showed the highest magnitude followed by PET and PTFE for the flat nozzle (21). Based on the theory of electrostatic forces, charged aerosols with similar polarity will repel each other; hence, induced plume expansion was expected. However, the results from high-speed laser image analysis have shown opposite plume angle trend for flat nozzle designs, where PTFE displaying the lowest negative charge magnitude (21) and the highest plume angle (Fig. 3). One possible explanation for this result could be the method used to detect aerosol electrostatic charges in the previous study. The Electrical Low Pressure Impactor (ELPI) can only produce net charge measurements for the particle at certain size ranges after the aerosol has passed through a USP throat. Therefore, the summarised net charge results for insulating materials like PET and PTFE can be biased due to neutralisation between bipolar charged aerosols (21). In addition, there is also no indication of the charge distribution for the aerosol droplets within the plume during the initial atomisation process, where plume angle images were measured (21). 
When formulation B was used (Fig. 4), the addition of 1\% ethanol to the propellant demonstrated plume angles with no significant difference between actuator materials, for both curved cone and curved flat nozzle designs. Whereas for cone nozzles, the PET actuator produced a significantly wider plume angle compared with aluminium and PTFE. The flat nozzle design with formulation B showed similar plume angles for aluminium and PET actuator compared with formulation $\mathrm{A}$, and a significant increase in plume angle was observed for the PTFE flat nozzle.

Aerosols generated from pMDI largely depend on the energy provided by the propellant in the formulation. The addition of a co-solvent, such as ethanol, can reduce the vapour pressure and lead to decreased plume angle and increased initial aerosol droplet size (23). Comparison of the plume angle for different material and nozzle designs for formulations A and B (Figs. 3 and 4 ) showed no significant differences. However, formulation $\mathrm{C}$ with $15 \%$ ethanol demonstrated a smaller plume angle, with both curved cone and curved flat nozzles, compared with formulation A and B (Fig. 5 ). These observations correlated with the reduced vapour pressure with increased ethanol concentration, but not for cone and flat nozzle designs. In a previous study, pMDI formulations containing co-solvent had reduced negative charges that could be associated with increasing ethanol concentrations, especially for curved nozzle designs with aluminium, PET and PTFE actuators (21). Therefore, aerosol plume formation and performance can be influence by not only the vapour pressure but also the electrostatic charges.

Significant differences were observed between the three actuator materials with formulation $\mathrm{C}$ for the cone nozzle, with the PTFE flat nozzle showing again the highest plume angle, similar to the results for formulation $\mathrm{A}$ and B (Figs. 3, 4 and 5). When a non-volatile component is included in the pMDI formulation, such as the active pharmaceutical ingredient BDP, it will form physicochemical interactions with the propellant and co-solvent, influencing the cavitation and evaporation of the generated aerosol droplets (23), and consequently the spray dynamic and plume geometry. This was confirmed by significantly reduced plume angle measurements across all materials and nozzle designs with formulation D (Fig. 6), except for the flat nozzles, compared with formulation C (Fig. 5).

In a previous study, curved cone and curved flat nozzles with PET and 
PTFE actuator materials produced reversed aerosol charge polarity and higher throat deposition with formulation $\mathrm{D}$, compared with normal cone and flat nozzle designs (21). One of the hypotheses for this observation is that the inclusion of a curved edge in the actuator design can induce plume expansion and increase contact charging with the actuator material's surface. This increased contact charging may result in the plume to becoming more bi-polar with a shift of one polarity to the edge of the plume. Ultimately, such an observation would result in higher deposition of the aerosols in the throat region (21). However, no significant difference in plume angles for curved nozzle designs was observed in this study (Fig. 6), which indicates that aerosol deposition for pMDIs is influenced dominantly by the electrostatic charges more than by the plume geometries, especially for the orothoracic region. On the other hand, the flat nozzle PTFE actuator showed persistent high plume angle across all four formulations, which could not be correlated with the aerosol electrostatic charge results (21).

\section{Effect of Nozzle Designs on Plume Geometries}

In general, both cone and flat nozzles produced variable plume angles across all pMDI formulations, compared with curved cone and curved flat nozzle designs (Figs. 3, 4, 5 and 6). Significant differences were observed for the same material and formulation when comparing the four types of nozzle designs, except for PET and PTFE with formulation A (Fig. 3 ), suggesting that nozzle geometry is important for aerosol plume geometry.

Significantly higher plume angles were observed with the PTFE flat nozzle compared with other materials and nozzle geometries, and have shown increased plume angle with increased ethanol concentration across formulation A, B and C (Figs. 3, 5 and 6). In a previous study, a flat nozzle with a different actuator generated variable aerosol static charges with similar drug deposition profile to the cone nozzle design (21), which could be related to increased surface interaction between aerosols and the flat nozzle surfaces caused by the expanded plume angle.

Further analyses with high-speed images have also shown a wider plume angle at the near orifice exit for PTFE flat nozzle, compared with aluminium and PET nozzles (Fig. 7) using formulation C. However, the plume angles for all pMDI actuations were measured using a single pre-set 
origin point, with plume expansion angle determined near the orifice exit that may not represent the overall plume geometries. Therefore, the spans of the fully formed plume at different distances from the origin were measured for all formulations and are shown in Fig. 8. In general, all actuator materials and nozzle designs have shown increased plume span with increased distance from the origin where plume span for PTFE flat nozzle has shown significant higher width compared with other actuator nozzles with formulation $\mathrm{C}$ and $\mathrm{D}$.

\section{Fig. 7}

Sample high-speed laser images (plume angle measurements with formulation $\mathrm{C}$ using aluminium, PET and PTFE flat nozzles). Cyan colour line represents the largest plume angle, and the magenta line represents the plume orientation in relationship to the origin point

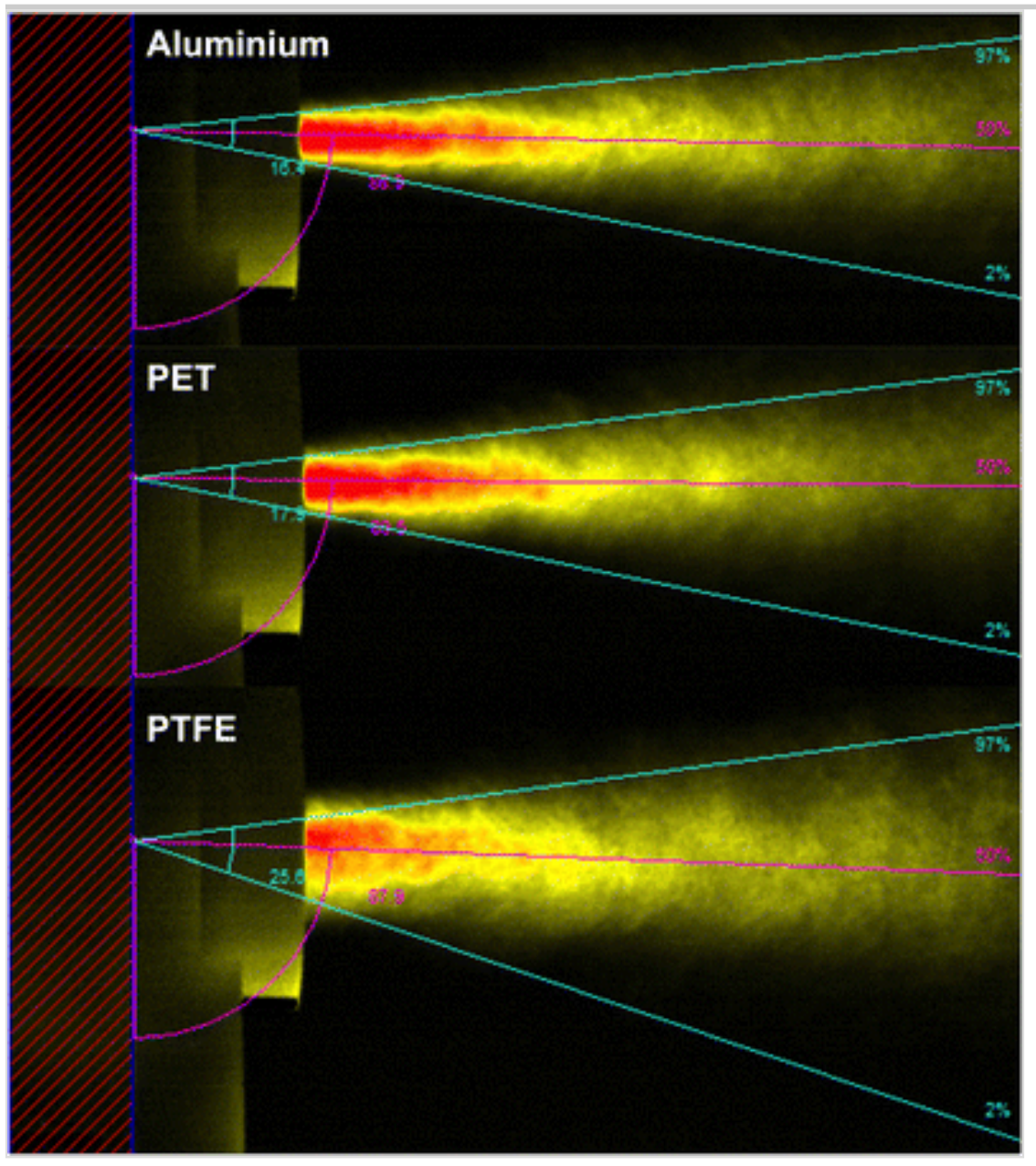

\section{Fig. 8}

Plume span measurements with formulations A, B, C and D using aluminium, PET and PTFE nozzles at the distance of 2, 4, 6 and $8 \mathrm{~cm}$ from the pre-set origin $(n=3 \pm \mathrm{SD})$ 
a

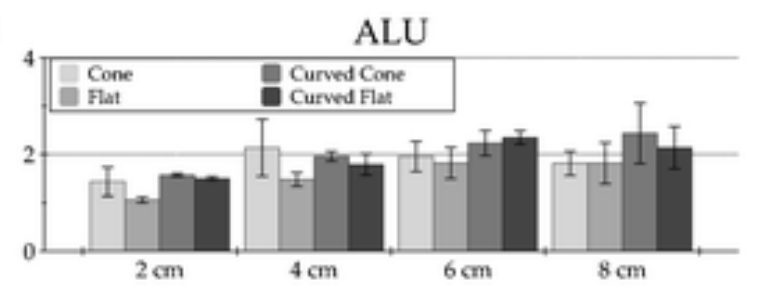

PET

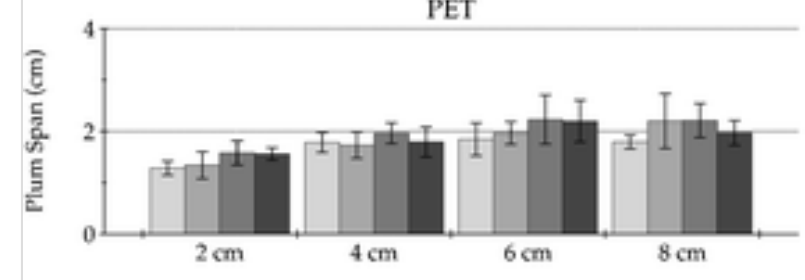

PTFE

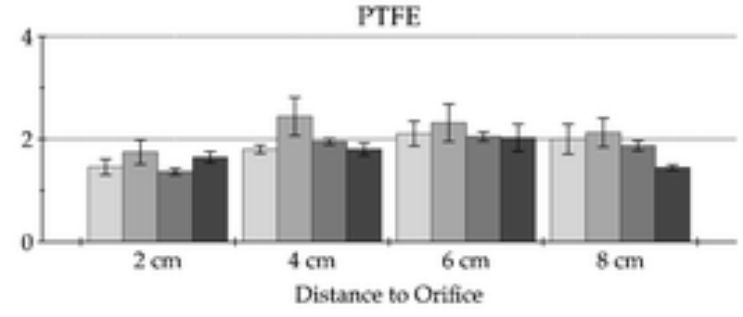

C

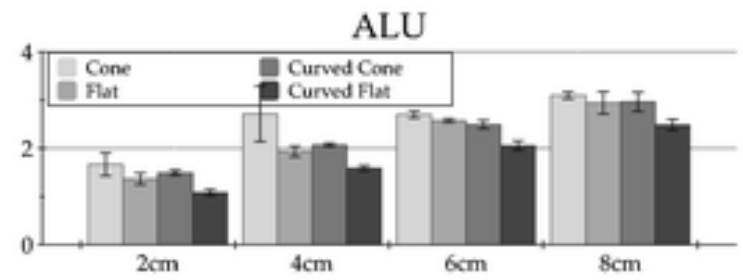

PET

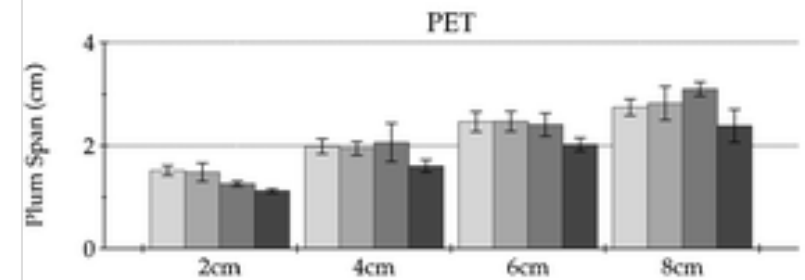

PTFE

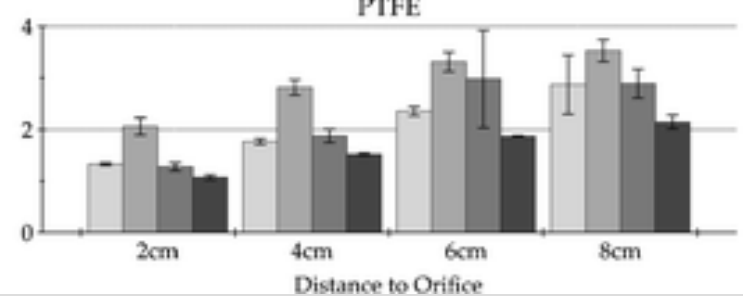

b

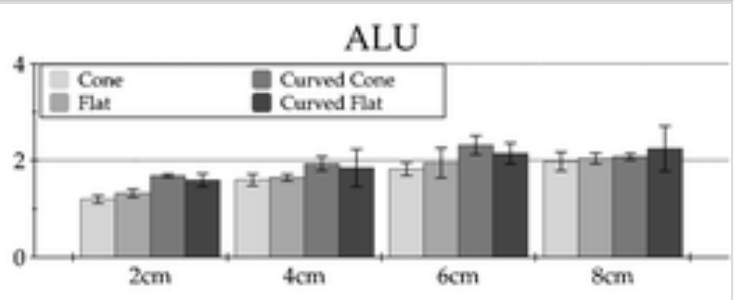

PET

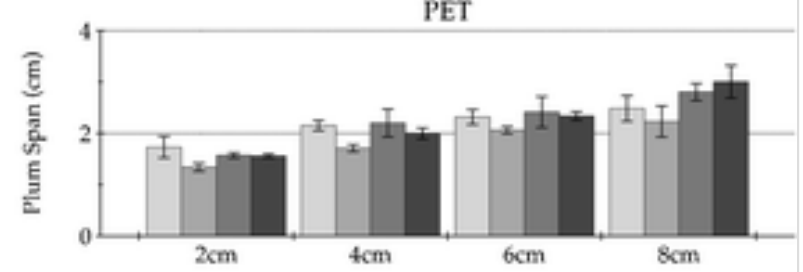

PTFE

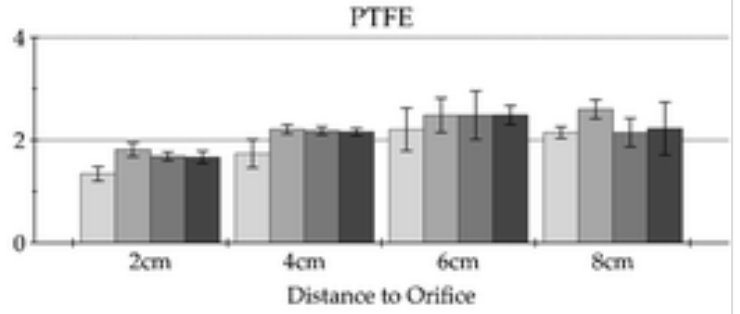

d

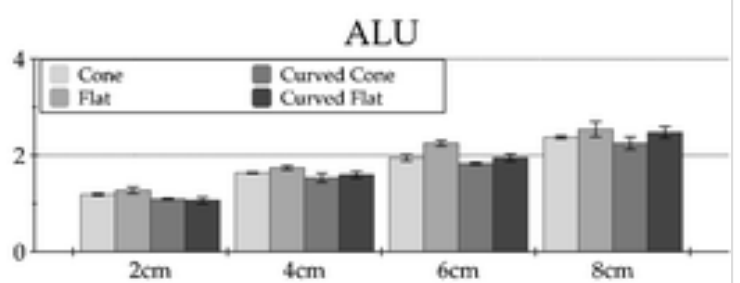

PET

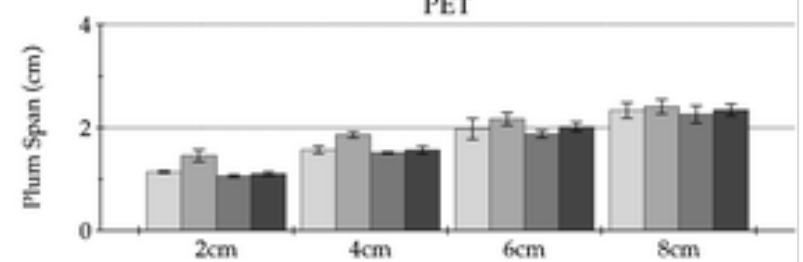

PTFE

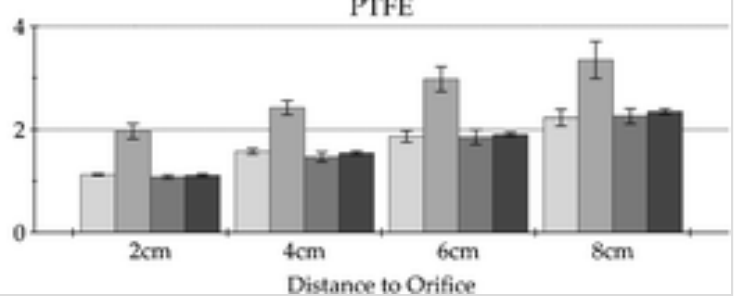

Plume geometry studies with different actuator nozzle for pMDI are still at their infancy due to the difficulties related to the transient and rapidly changing atomisation process. However, this technique is well established in fuel and spray industries, where it has been demonstrated that plain orifice atomiser (flat nozzle) can have very complex internal flows and external atomisation mechanics (24); this is often referred to as plain orifice atomiser model.

In an ideal spray system with a flat nozzle, the liquid jet should completely fill the nozzle orifice and the aerosol plume generated will depend on the 
orifice diameter. However, in pressurised systems with volatile propellant, such as pMDIs, the propellant flash boiling after its emission from the canister will cause bubbling of the liquid propellant, creating vapour pockets near the inlet surface of the nozzle (Fig. 9) $(25,26)$. These vapour pockets will generate an internal pressure on the flowing liquid jet that will cause higher gradient changes after the orifice exit, where the plume will expand more dramatically, such as observed in PTFE flat nozzle (Fig. 7). When a curved edge is included in the nozzle geometry, there is a reduced gradient in the sudden constriction of the nozzle exit; hence, lower plume expansion will be achieved.

\section{Fig. 9}

Schematic cavitation flow model for the flat nozzle geometry (25)

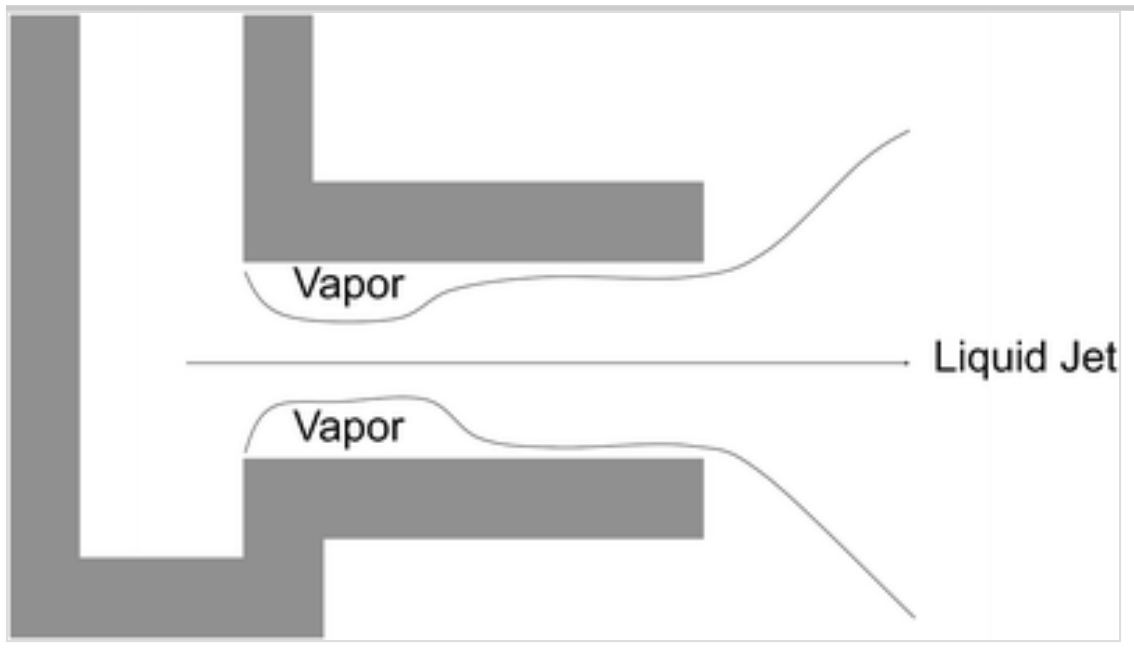

On the other hand, the cone and curved cone nozzles contain outer expansion in their geometries. This cone shape will provide regions for vapour recirculation and generates extra pressure on the initial plume after its exit (Fig. 10). Therefore, the plume angle produced by the cone and curved cone nozzles will be smaller compared with the flat nozzle, as demonstrated by the results (Figs. 3, 4, 5 and 6).

Fig. 10

Schematic recirculation flow model for the cone nozzle geometry (24) 


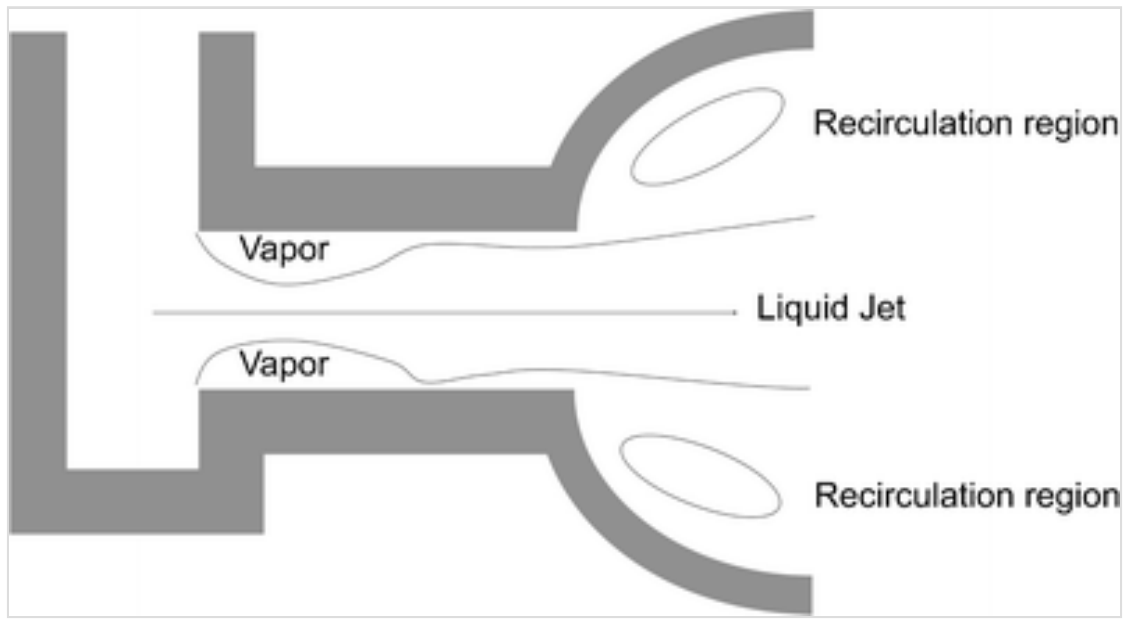

The proposed plain orifice cavitation model can only be observed for actuator material PTFE; consequently, it is believed that the results could be influenced by the material properties. PTFE, otherwise known as Teflon ${ }^{\mathrm{TM}}$, has a very hydrophobic surface. When hydrophobic liquids such as HFA 134a come into contact with the PTFE surface, it will decrease the contact angle allowing the liquid jet to completely fill the nozzle and produce a controlled plume angle, such as in formulation A (Fig. 3). When ethanol is introduced into the formulation, the hydrophobicity of the liquid mixture is reduced, increasing the contact angle between the propellant and the actuator surface. This incomplete contact promotes cavitation that generates an internal pressure on the flowing aerosol stream and is correlated with the concentration of hydrophilic component (e.g. Ethanol). As a result, for the PTFE flat nozzle, increased plume angles with increased ethanol were observed (Figs. 4, 5 and 6). However, one other parameter that should be considered is the diameter of the commercial pMDI actuator nozzles. Generally, this ranges from 0.14 to $0.6 \mathrm{~mm}$ (27) and the flash boiling atomisation is a rapid process. Therefore, it is unknown whether there are opportunities for these hypothesised hydrophobic/hydrophilic interactions between liquid formulation and the actuator surface to cause changes in plume geometry during such limited length and short transit times.

\section{CONCLUSIONS}

In summary, this study has shown that high-speed laser image system is a suitable method for analysis of pharmaceutical pressurised aerosols. It can potentially provide valuable information regarding to plume geometry and can assist the development of inhalation therapies. For the current study, high-speed images have shown that the plume geometry of pMDIs can be 
influenced by the vapour pressure, nozzle geometry and actuator materials. However, correlation between aerosol performance, plume angles and nozzle designs cannot be established due to the lack of simultaneous aerosol deposition analysis with the high-speed laser imaging. At the same time, pressurised aerosols could be influenced by other physical and chemical interactions between device surface and the formulations, such as electrostatic charges. The high-speed imaging analysis used in the study was not able to provide direct measurement of the electrostatic profile for the plume, but it has the potential to provide detailed analysis of aerosol intensity and droplet morphologies that can be useful to predict static interaction for pMDI aerosols.

\section{Acknowledgments}

This research was supported by the Australian Research Council Linkage Project funding scheme (project number ARC-LP100200156) and Chiesi Ltd, Chippenham, Wiltshire, UK. Professor Traini is the recipient of an Australian Research Council Future Fellowship (project number FT12010063). Professor Young is the recipient of an Australian Research Council Future Fellowship (project number FT110100996).

\section{References}

\section{$\mathrm{AQ}_{4}$}

1. Thiel C. From Susie's question to CFC free: an inventor's perspective on forty years of MDI development and regulation. Respir Drug Deliv. 1996;1:115-24.

2. Bell J, Newman S. The rejuvenated pressurised metered dose inhaler. Expert Opin Drug Deliv. 2007;4:215-34.

AQ5

3. Newman SP. Principles of metered-dose inhaler design. Respir Care. 2005;50(9):1177-90.

4. Kim CS, Eldridge MA, Sackner MA. Oropharyngeal deposition and delivery aspects of metered-dose inhaler aerosols. Am Rev Respir Dis. 1987;135(1):157-64.

5. Sunita L. An overview on: pharmaceutical aerosols. Int Res J Pharm. 
6. FDA. Guidance for Industrv Metered Dose Inhaler (MDI) and Dry Powder Inhaler (DPI) Drug Products. Center for Drug Evaluation and Research (CDER). 1998;

http://www.fda.gov/ohrms/dockets/ac/00/backgrd/3634b1c_sectiond.pdf

7. Hünerbein B, Kala H, Moldenhauer H. Aerosols and sprays.

Pharmazie. 1978;33(12):824-31.

8. Benjamin EJ, Kroeten JJ, Shek E. Characterization of spray patterns of inhalation aerosols using thin-layer chromatography. J Pharm Sci. $1983 ; 72(4): 380-5$.

9. Smyth H, Hickey A, Brace G, Barbour T, Gallion J, Grove J. Spray pattern analysis for metered dose inhalers I: orifice size, particle size, and droplet motion correlations. Drug Dev Ind Pharm. 2006;32(9):1033-41.

10. Crosland BM, Johnson MR, Matida EA. Characterization of the spray velocities from a pressurized metered-dose inhaler. J Aerosol Med Pulm Drug Deliv. 2009;22(2):85-98.

11. Oliveira RF, Teixeira S, Teixeira JC, Silva LF, Antunes H. pMDI sprays: theory, experiment and numerical simulation. 2012.

12. Kakade PP, Versteeg HK, Hargrave GK, Genova P, Williams Iii RC, Deaton D. Design optimization of a novel pMDI actuator for systemic drug delivery. J Aerosol Med. 2007;20(4):460-74.

13. Naqwi AA, Durst F. Light scattering applied to LDA and PDA measurements. Part 1: theory and numerical treatments. Part Part Syst Charact. 1991;8(1-4):245-58.

14. Naqwi AA, Durst F. Light scattering applied to LDA and PDA measurements Part 2: computational results and their discussion. Part Part Syst Charact. 1992;9(1-4):66-80. 
15. Stobart R, Childs PR. Total vehicle technology: how do we get the innovation back into vehicle design. John Wiley \& Sons; 2002.

16. Tuck C, Ellis M, Miller P. Techniques for measurement of droplet size and velocity distributions in agricultural sprays. Crop Prot. 1997;16(7):619-28.

17. Johal B, Murphy S, Marshall J. Plume characteristics of fluticasone propionate/formoterol pMDI compared with fluticasone propionate/salmeterol pMDI. Eur Respir J. 2013;42 Suppl 57:4132.

18. Miller PC, Tuck CR, Murphy S, da Costa Ferreira M, editors. Measurements of the droplet velocities in sprays produced by different designs of agricultural spray nozzle. European Conference on Liquid Atomization and Spray Systems, Como Lake, Italy; 2008.

19. Kwok PCL, Chan HK. Electrostatics of pharmaceutical inhalation aerosols. J Pharm Pharmacol. 2009;61(12):1587-99.

20. Chen Y, Young PM, Fletcher DF, Chan HK, Long E, Lewis D, et al. The influence of actuator materials and nozzle designs on electrostatic charge of Pressurised Metered Dose Inhaler (pMDI) formulations. Pharm Res. 2014;31(5):1325-37.

21. Chen Y, Young P, Fletcher D, Chan HK, Long E, Lewis D, et al. The effect of actuator nozzle designs on the electrostatic charge generated in pressurised metered dose inhaler aerosols. Pharm Res. 2014:1-12.

22. Diaz AF, Felix-Navarro RM. A semi-quantitative tribo-electric series for polymeric materials: the influence of chemical structure and properties. J Electrost. 2004;62(4):277-90.

23. Vervaet C, Byron PR. Drug-surfactant-propellant interactions in HFA-formulations. Int J Pharm. 1999;186(1):13-30.

24. Lefebvre A. Atomization and sprays. CRC press; 1988.

25. Sou A, Hosokawa S, Tomiyama A. Effects of cavitation in a nozzle 
on liquid jet atomization. Int J Heat Mass Transf. 2007;50(17):3575-82.

26. Tamaki N, editor. Effects of cavitation in a nozzle hole on atomization of spray and development of high-efficiency atomization enhancement nozzle. Proceedings the 11th international conference on liquid atomization and spray systems, paper; 2009.

27. Brambilla G, Ganderton D, Garzia R, Lewis D, Meakin B, Ventura P. Modulation of aerosol clouds produced by pressurised inhalation aerosols. Int J Pharm. 1999;186(1):53-61. 